\title{
Variações do "amor cortês" em Leonor de Mendonça e em O casamento de Fígaro
}

\section{Vilma Arêas}

\begin{abstract}
Resumo: Este texto tece considerações sobre duas peças, Leonor de Mendonça, de Gonçalves Dias, e $\mathrm{O}$ casamento de Fígaro, de Beaumarchais, a partir da coincidência, nelas, de duas cenas amorosas nos moldes do amor cortês. Palavras-chave: Gonçalves Dias, Leonor de Mendonça, Beaumarchais, O casamento de Fígaro.
\end{abstract}

Abstract: This paper proposes a commentary about two plays, Leonor de Mendonça, by Gonçalves Dias, and The marriage of Figaro, written by Beaumarchais, from the coincidence of two love scenes conceived in a dialog with courtly love. Keywords: Gonçalves Dias, Leonor de Mendonça, Beaumarchais, The marriage of Figaro. 
A Yara Frateschi Vieira, pelas informações, sugestões e, mais que tudo, pela amizade.

A imaginação tem cores que se não desenham.

Gonçalves Dias, Prólogo a Leonor de Mendonça

Se desejarmos de fato entender a realidade, é necessário ir além das razões oficiais, sondando os motivos obscuros.

Décio de Almeida Prado

\section{Introdução}

Obedecendo ao programa de retomada dos valores medievais, a época romântica fez renascer certa concepção do que se entende por "amor cortês", termo introduzido na filologia moderna em 1883 por Gaston Paris. ${ }^{1}$ Mas esse fenômeno social e literário não surgiu com ele. Ao contrário, o amor cortês possui uma longa duração, não se limitando às cortes medievais europeias. Contudo, a inevitável diversidade de suas realizações abalou conceitos mais ou menos estáveis a partir do século xx, quando então novas perspectivas históricas, sociológicas e psicanalíticas ${ }^{2}$ foram levadas em consideração ao lado da teoria dos gêneros, chegando-se ao limite da dúvida quanto à viabilidade do uso do termo. ${ }^{3}$ Será que ele se refere a um movimento literário ou a uma instituição social? Significa um culto da castidade ou um anteparo para o adultério?

Cf. PARIS, Gaston. Études sur les romans de la Table Ronde - Lancelot du Lac- II. Le Conte de la Charrette. In: Romania $12^{\mathrm{e}}$ année, 1883. Neste ensaio G. Paris nomeia e estabelece as características do "amour courtois" tal como surge, pela primeira vez, no "Conte de la Charrette" de Chrétien de Troyes, apontando-Ihe também as possíveis origens. Cf. também R. Schnell, "L'amour courtois en tant que discours courtois sur l'amour". In Romania, 118 année, 1989, tomo 110.

Para uma interpretação psicanalítica do amor cortês, que comumente revela o impossível encontro com o objeto, constituindo paradigma da sublimação da interdição sexual, cf. ZAVALA, Iris M. Leer el Quijote, siete tesis sobre ética y literatura. Barcelona: Anthropos, 2005. Cf. também BOASE, Roger. The origin and meaning of courtly love. UK/USA: Manchester University Press, 1977, primeiro capítulo.

3 Cf. KOEHLER, Erich. Observations historiques et sociologiques sur la poésie des troubadours. In: Cahiers de Civilisation Médievale X-XII siècles, tomo XVII, Université de Poitiers, 1964, e Deliberations on a theory of the genre of the Old Provençal Descort. In: Italian Literature- roots and branches. New Haven and London: Yale University Press, 1976. Cf. também Francis L. Utley, Must we abandon the concept of courtly love? (apud SCHNELL, R., L'amour courtois en tant que discours courtois sur l'amour. In: Romania, 118e année, 1989, tomo 110).

Teresa revista de Literatura Brasileira [12|13]; São Paulo, p. 226-243, 2013 • 227 
Não é novidade que Gonçalves Dias apoiou seu drama Leonor de Mendonça numa variação desse amor estilizado, realização suprema de uma classe cujas noções morais e intelectuais estavam contidas numa espécie de ars amandi. ${ }^{5}$ Cedendo ao mesmo "espírito de experimentação arcaizante", observado por Vagner Camilo em seu ensaio sobre as Sextilhas de Frei Antão, ${ }^{6}$ o poeta voltou-se mais uma vez ao passado. Encontrou inspiração para seu drama num curto romance histórico em versos, A duquesa de Bragança, publicado na Revista Literária, que começou a circular em 1838, justamente no ano em que o poeta chegou a Portugal. O romance tematiza a morte de Leonor de Mendonça em 1512, assassinada pelo marido, d. Jaime, duque de Bragança, por suspeita de adultério. É fácil observar que, sem os valores medievais passados pelo filtro do romantismo, não se entenderia bem a peça de Gonçalves Dias. O recuo no tempo e no espaço é também característico das outras três obras teatrais do escritor, unidas, além disso, pelo mesmo desenlace sangrento: Patkull, 1707, tem como cenários Mecklenburg (Alemanha), Dresden (Saxônia) e Casimir (Polônia); Beatriz Cenci, 1598, acontece na Itália; Boabdil, no fim do domínio mouro, em Granada.

As observações que se seguem se originaram na percepção de traços pontuais e coincidentes numa cena de sedução, com seus desdobramentos nos moldes do amor cortês, envolvendo uma mulher casada e um homem jovem, ${ }^{7}$ como se pode perceber em Leonor de Mendonça, drama acima referido, e numa comédia em cinco atos de Beaumarchais, $O$ casamento de Fígaro, ${ }^{8}$ distando mais de meio século uma peça da outra.

DIAS, Antônio Gonçalves (1823-1864). Leonor de Mendonça (1846), "drama em prosa", publicado no ano seguinte pelo Arquivo Teatral. As citações feitas neste trabalho são do texto completo publicado pela Editora Vega, Belo Horizonte, 1976, de acordo com a primeira edição, H. Garnier, Rio de Janeiro/Paris, 1868.

5 Cf. HUIZINGA, Johan. O declínio da Idade Média. Tradução de Augusto Abelaira. São Paulo: Verbo/Edusp, 1978, especialmente cap. 8, “O amor estilizado", p. 101 ss: “Do mesmo modo que a escolástica representa o grande esforço do espírito medieval para unir todo o pensamento filosófico num centro único, assim a teoria do amor cortês, numa esfera menos elevada, tende a englobar tudo o que se relaciona com a vida nobre".

6 CAMILO, Vagner. Nos tempos de antão. Considerações sobre as Sextilhas de Gonçalves Dias. Revista USP nº 40, dez.-jan.-fev. 1998-9.

7 Cherubino é um adolescente e Alcoforado, muito jovem, não havia ainda cingido a espada.

8 BEAUMARCHAIS, Pierre-Augustin Caron de (1732-1799). La folle journée ou Le mariage de Figaro (1784). In: Oeuvres (éd. établie par Pierre Larthomas/Jacqueline Larthomas). Paris: Gallimard, 1988. Também As bodas de Fígaro - Mozart, Da Ponte, Beaumarchais - ed. bilíngue do libreto e da peça (trad. de Antônio Monteiro Guimarães e Sergio Flaksman). Rio de Janeiro: Jorge Zahar, 1991. A comédia faz parte de uma trilogia começada com Le barbier de Séville (1775) e terminada pelo drama La mère coupable (1792), com sua 
Além da cena referida, outra coincidência as une: a peça de Beaumarchais foi levada à cena em 1784, após seis anos de interdição, ${ }^{9}$ e Leonor de Mendonça, escrita em 1846, esperou mais de um século para subir aos palcos dos centros representativos de nosso país, ${ }^{10}$ apesar das esperanças do autor e de suas inúteis tentativas em 1847 para conseguir que João Caetano a encenasse. Supõe-se que a recusa do ator e empresário se deveu ao papel principal ser atribuído a uma mulher. Ou terá sido, quem sabe, pela exposição da brutalidade exercida pela nobreza, sobretudo pela organização do poder patriarcal? Não nos esqueçamos de que a corte portuguesa estava no Brasil àquela época. A mesma temática havia sido desenvolvida por Beaumarchais, criando empecilhos para a exibição de sua obra em Paris, conforme observei acima. Ao articular as duas peças, quero deixar claro que não tive a intenção de investigar influências, aliás difíceis de serem asseguradas e até certo ponto insensatas, se levarmos em conta a complexidade da trilogia de Beaumarchais, da qual Le mariage de Figaro ocupa o centro, desenrolando-se o conjunto das peças nos moldes de um longo romance. ${ }^{11}$ As situações históricas dos autores também não podem ser aproximadas: Pierre-Augustin Caron (que passou a se chamar "Monsieur de Beaumarchais" depois de se introduzir na corte de Louis $\mathrm{Xv}^{12}$ e mais tarde, Beaumarchais-Figaro, por conta do sucesso da comédia) viveu aventurosamente nos agitados anos que antecederam a Revolução Francesa. Sua peça, de enorme repercussão internacional, lhe valeu o cárcere, embora tenha tido 68 récitas, número quase incrível para a época. Dois anos depois da estreia, Mozart compôs a música da ópera, com libreto de Lorenzo Da Ponte.

"profonde et touchante moralité," após o desterro de quatro anos do autor. (Cf. BEAUMARCHAIS. Un mot sur La mère coupable. In: Oeuvres. Op. cit., p. 600 ss.

9 A peça foi terminada em 1778 e só representada seis anos depois, tendo sido lida por seis censores entre 1781 e 1784. Foi de Louis XVI a maior reprovação: "É detestável, jamais será representada. Seria necessário destruir a Bastilha para que a representação desta peça não fosse uma perigosa inconsequência. Este homem abala tudo o que é necessário respeitar num governo" (Mme. Campan, preceptora dos filhos de Louis XVI, Mémoires, t. I, 1928 - apud Apresentação de Élisabeth Lavezzi a Le mariage de Figaro. Paris: Flammarion, 1999).

10 Leonor de Mendonça foi encenada em 1957 pelo Teatro Brasileiro de Comédia, dirigida por Ziembinski (apud Introdução de Marlene de Castro Correia a Gonçalves Dias teatro completo. MEC/Fundação Nacional de Arte/Serviço Nacional de Teatro, 1979), que acrescenta a informação de Manuel Bandeira sobre a encenação da peça em 1848, em São Luís do Maranhão.

Beaumarchais foi professor de música das filhas de Louis XV e aperfeiçoou a harpa, para o que certamente foi útil sua profissão primeira de relojoeiro; suas relações com o financista Pâris-Duverney o enriqueceram; comprou então o posto de conselheiro secretário do rei, que Ihe conferiu nobreza; também viajou a negócios à Espanha, cenário de suas comédias. 
Tal agitação passou longe de Gonçalves Dias, apesar de sua peça, segundo Décio de Almeida Prado, ser "uma das poucas obras-primas do teatro brasileiro",13 "a melhor obra do gênero em nossa literatura dramática do século XIX”, nas palavras de Sábato Magaldi, ${ }^{14}$ "a imortal, divina Leonor", segundo Ruggero Jacobbi. ${ }^{15} \mathrm{O}$ "Prólogo" que o poeta escreveu para a obra é também uma página de inteligência e lucidez: discute as razões da censura que considerou sua Beatriz Cenci imoral, pondera a distância existente entre intenção e execução no trabalho literário, expõe seus pontos de vista teóricos, define o drama segundo o prefácio de Cromwell de Victor Hugo, ${ }^{16}$ e faz a ideia de fatalidade baixar do céu à terra, "aquela fatalidade que nada tem de Deus e tudo dos homens", segundo suas próprias palavras.

No "Prefácio" a Le mariage de Figaro, Beaumarchais já expusera e discutira pormenorizadamente a questão dos gêneros e as razões equivocadas da censura às suas duas comédias.

O mais grave na pretendida aproximação é não termos provas de Gonçalves Dias haver lido ou assistido à peça de Beaumarchais, apesar de seus estudos em Coimbra de 1838 a 1844, de suas férias em Lisboa e de ter estado na Espanha, França, Bélgica, Alemanha e em outros países europeus mais de uma vez. Mas é quase certo que tenha conhecido a ópera, não só porque passou longas temporadas em Paris, como pela grande paixão da Coroa portuguesa pelos espetáculos líricos, gosto herdado por nossos intelectuais do século XIX. Gonçalves Dias se alinha junto a esses, também na autoria de folhetins dedicados ao gênero.

Ao ler o prefácio de Leonor de Mendonça, Décio de Almeida Prado compreendeu o sentido da reflexão do poeta a respeito da alternância do verso e da prosa no teatro de Shakespeare, que assim fazia atendendo à diversidade de tons possíveis numa composição teatral. Gonçalves Dias gostaria de imitá-lo, imaginava o efeito da variação, mas ainda não confiava na própria competência.

PRADO, Décio de Almeida. O drama romântico brasileiro. São Paulo: Perspectiva, 1996, $3^{\circ}$ cap.

MAGALDI, Sábato. Panorama do teatro brasileiro. MEC/DAC/FUNARTE, Coleção Ensaios, s.d, p. 74.

15 JACOBBI, Ruggero. Goethe Schiller Gonçalves Dias. Porto Alegre: Edições da Faculdade de Filosofia, 1958, p. $41,58,68$.

16 Lothar Hessel e Georges Raeders observam que em 1838, data da chegada de Gonçalves Dias a Coimbra, ainda estavam vivos os ecos da "batalha do Hernani", de Victor Hugo, em 1830. No mesmo ano de 1838 estreou Um auto de Gil Vicente, de Garrett, o restaurador do teatro nacional português. (HESSEL, Lothar; RAEDERS, Georges. O teatro no Brasil sob d. Pedro Il. Porto Alegre: Coedições URGS, 1979, p. 92-3). 
[...] está me parecendo que, se quando a plateia esperasse ansiosa o desfecho de uma cena, de um ato ou do drama, mudassem os atores repentinamente de linguagem, e trovejassem ao mesmo tempo o verso nos lábios dos atores e a música em todos os instrumentos da orquestra, haveria na plateia tal fascinação que devia esmorecer por fim num bater prolongado de bravos. ${ }^{17}$

Grande conhecedor da ópera, Décio assim interpretou as palavras de Gonçalves Dias: "O efeito visado pelo poeta compara-se ao proporcionado pela ária, após os recitativos na ópera italiana, quando o lirismo sobe formalmente de nível". ${ }^{18}$ Desse modo, podemos considerar Gonçalves Dias um conhecedor sensível do gênero, a ponto de desejar aplicar efeitos shakespearianos e operísticos em Leonor de Mendonça, medindo falas pelo efeito musical que poderiam causar: "A voz de Alcoforado suplicando a vida da duquesa seria como uma harpa em uma orquestra, a voz da duquesa como um acorde mavioso, a voz do duque e dos da sua comitiva como um acompanhamento fúnebre e pavoroso". ${ }^{19}$

Se não encontrei entre nós referências à ópera Les noces de Figaro, ${ }^{20}$ baseada na comédia, por outro lado são de notar as observações feitas na época a respeito de Le barbier de Séville, do mesmo autor, mencionado inúmeras vezes nos Folhetins de Martins Pena, sempre assinalando os equívocos de sua execução entre nós. Contemporâneo de Gonçalves Dias, e incansável denunciador do atraso colonial, em 23 de março de 1847 Pena não deixou de citar a proibição da ópera pelo Conservatório Dramático, com o argumento de ser tempo da Quaresma. Sarcasticamente o folhetinista observou que provavelmente "barbeiro que seduz pupilas, e tutor que as deixa roubar, não têm nada de edificante". ${ }^{21}$

Além dessas circunstâncias censórias, podemos acrescentar mais uma vez os comentários de Décio de Almeida Prado ${ }^{22}$ a respeito das dificuldades de nosso teatro com a encenação de espetáculos líricos: se o teatro português e o brasileiro tinham alguma experiência do canto e da dança adquirida no entremez, "a opereta, no entanto, desdobrava-se num nível sensivelmente superior” exigindo um demorado aprendizado

17

18

19

20 qual não temos traços.

21 PENA, Martins. Folhetins - a semana lírica. Rio de Janeiro: MEC/INL, 1965, p. 183

22

Teresa revista de Literatura Brasileira [12|13]; São Paulo, p. 226-243, 2013 • 231 
prático e teórico. "Era música para gargantas inteiras e não para as vozes de meia garganta que Eça de Queirós, com certa maldade, viu nos cantores de Portugal.” A solução encontrada pelo Brasil no final do século foi tomar emprestadas da Europa vozes que iam "da canção à ópera, passando pela opereta e pela ópera-cômica, enquanto o Brasil entrava com a sua comicidade, nem sempre fina como a parisiense".

É a isso que se refere Martins Pena em meados dos Oitocentos, ao comparar a encenação de $O$ barbeiro de Sevilha a uma farsa que deveria ser intitulada $O$ barbeiro barbeando o burro. ${ }^{23}$

Apesar desse panorama, temos de considerar, repito, as longas temporadas de Gonçalves Dias passadas na Europa, onde ao fluxo de informações artísticas se acrescentava a possibilidade de proximidade das matrizes cultas da sensibilidade moderna, formadas nos primeiros decênios do século XIX.

Tanto Beatriz Cenci (1843) quanto Leonor de Mendonça (1846) foram antecedidas por crônicas saídas em revistas portuguesas da época, o que mostra o poeta atento aos interesses de seu tempo. Além disso, as referências a grandes dramaturgos, a leitura de Chatterton, de Alfred de Vigny, enquanto escrevia seu drama, a tradução de A noiva de Messina, de Schiller, feita por ele ${ }^{24}$ tudo isso faz de nosso poeta um conhecedor do palco, com informação diferenciada em nosso meio.

\section{Acasos?}

Direi pois, não o que fiz, mas o que prometi fazer.

Gonçalves Dias, Prólogo a Leonor de Mendonça

Leonor de Mendonça é um drama, cuja composição se apoia na concentração de situações e caracteres, tendo em seu centro uma cena cômica, assim considerada por se limitar ao nível familiar, quebrando a gravidade dos atos que a circundam. Tal estrutura é intencional e foi comentada no "Prólogo" pelo autor, que tem a noção de que a essência da comédia não é o riso: "descreva ela fielmente os costumes, e a

PENA, Martins. Folhetins - a semana lírica. Op. cit. p.11. Para demais comentários do folhetinista a respeito da representação dessa ópera, e da citação em tableau que dela faz em duas de suas comédias (O judas em sábado de aleluia e As desgraças de uma criança). Cf. ARÊAS, V. Na tapera de Santa Cruz. São Paulo: Martins Fontes, 1987.

24 Há uma nova edição da peça pela Cosac Naify, 2004, organizada por Márcio Suzuki e Samuel Titan Jr., com notas de Manuel Bandeira, a que se acrescenta um apêndice substancioso. 
arte ficará satisfeita". ${ }^{25}$ A trama se organiza entre o casal nobre, o duque d. Jaime e d. Leonor, mais o enamorado da mulher, Antonio Alcoforado. Os poucos coadjuvantes, com a exceção de Fernão Velho, que denuncia Leonor, apenas modulam o ritmo da ação conforme convinha ao drama da época.

Em O casamento de Fígaro, por outro lado, temos uma comédia sem misturas, embora a possamos considerar "séria" na concepção de Diderot, ${ }^{26}$ "le cher Diderot" de quem Beaumarchais se considerava discípulo; segundo ambos, a peça séria teria por objeto a virtude e os deveres dos homens, não seus ridículos; o Conde é punido justamente por faltar a seus deveres e exorbitar de seu poder.

A dramaturgia lança mão da multiplicação de personagens, além das máscaras, disfarces e esconderijos, ${ }^{27}$ que os desdobram e entrecruzam: os criados, Fígaro e Suzanne, serviçais dos aristocratas, o conde de Almaviva e Rosina, mais Cherubino, habitante do reino das máscaras; os demais coadjuvantes - inclusive o casal mais velho - estão firmemente ajustados à relojoaria azeitada do enredo - para prestarmos homenagem à profissão primeira de Beaumarchais.

Tal clareza de propósitos e de execução, assinalados pelo autor na defesa da moralidade de sua peça, inclui também o tom severo que existe nela:

[...] um senhor feudal, corrupto o bastante para desejar prostituir a seu capricho tudo o que lhe é subordinado, para se aproveitar, em seus próprios domínios, da pudicícia de seus jovens vassalos, deve acabar, como este aqui, por ser alvo da zombaria dos criados. ${ }^{28}$

É tempo de destacar as duas cenas que me chamaram a atenção nas duas obras citadas: a primeira, a que se inicia no quadro I do primeiro ato, cena 3 de Leonor de Mendonça, marcando o início do envolvimento emocional da Duquesa com Alcoforado, "belo mancebo", segundo a camareira, na quadra da "verde juventude", segundo d. Jaime.

DIAS, Gonçalves. Prólogo a Leonor de Mendonça. Op. cit., p. 9.

26 Cf. DIDEROT, Denis. Discurso sobre a poesia dramática. Trad., org., apresentação e notas de Franklin de Mattos. São Paulo: Cosac Naify, 2005, p. 28.

27 J. Scherer, em La dramaturgie de Beaumarchais (no dossiê de Élisabeth Lavezzi, op. cit., p. 258) comenta o desdobramento de um "terceiro lugar" que o dramaturgo nos força a imaginar por meio do esconderijo. (Cf. ARÊAS, V. Na tapera de Santa Cruz, op. cit., p. 89, observações sobre o "fundo falso" existente em O judas em sábado de aleluia, de Martins Pena).

28 "C'est qu'un seigneur assez vicieux pour vouloir prostituer à ses caprices tout ce qui lui est subordonné, pour se jouer dans ses domaines de la pudicité de toutes ses jeunes vassales, doit finir, comme celui-ci, par être la risée de ses valets". Préface a Le mariage de Figaro. In: OEuvres, op. cit. p. 362.

Teresa revista de Literatura Brasileira [12|13]; São Paulo, p. 226-243, 2013 • 233 
Mas o que me interessa na pintura é o que está disposto com menos nitidez, isto é, o clima tenso criado por Gonçalves Dias, no momento em que põe a protagonista, "malmaridada", para usar um termo da lírica medieval, a contracenar com esse cavaleiro. Ao perceber o "amor louco" do rapaz, apesar do medo a Duquesa parece lisonjeada, e sem dúvida absolutamente confusa: deseja que a criada permaneça e a manda embora, despede o cavaleiro ao mesmo tempo em que o retém com perguntas sobre sua família. ${ }^{29}$ Algumas cenas depois, ao se findar o quadro, após se comprometer a ir a uma caçada com o marido, ouvimos a personagem murmurar de si para si, sonhadora: "Ele irá também conosco; eu o adivinho... Vê-lo-ei pela última vez".

A situação havia sido preparada pela cena anterior, entre Leonor e sua camareira Paula, a respeito da fita roubada por Alcoforado e usada no barrete à guisa do "serviço" amoroso prestado à dama, segundo o código cavaleiresco e a maneira provençal. A informação de Paula ("Ele julgou que a fita fosse minha") faz Leonor dizer num à parte: “Vaidosa!", antes se revelando ao leitor/espectador do que criticando a camareira, pois no final do ato as últimas palavras da Duquesa provam que ela já notara o rapaz e já lutava com a própria inclinação amorosa: "Não gosto de ouvir falar nele, e não posso pensar em outra coisa. Por quê? (Torna-se pensativa)".

Em $O$ casamento de Fígaro acontece algo semelhante, embora com maior sutileza, a começar pela primeira cena do segundo ato quando a Condessa, do mesmo modo desprezada pelo marido, toma conhecimento, por intermédio de sua camareira Suzanne, da paixão do pajem Cherubino por ela. Adolescente e "damerino", isto é, mulherengo, Cherubino funciona como uma espécie de símbolo do despertar amoroso. Ele tem treze anos, talvez não seja mais uma criança, mas ainda não é um homem, afirma Beaumarchais, explicando que escolhera a idade de propósito, para que o personagem despertasse interesse "sans forcer personne à rougir". ${ }^{\circ} \mathrm{Na}$ ópera de Mozart e Da Ponte é ele quem entoa a famosa ária Voi che sapette che cosa è l'amore, versos inspirados na Vita nuova de Dante. ${ }^{31}$

29 As mesmas indecisões e imprecisões se dão na última e fatal entrevista, quando Leonor confessa seu amor, ao mesmo tempo em que leva o cavaleiro à cabeceira dos filhos adormecidos, para se referir à orfandade do rapaz e afirmar que queria servir-lhe de mãe e de irmã. (Cf. DIAS, Gonçalves. Leonor de Mendonça, ato III, quadro IV, cena 1).

30 BEAUMARCHAIS, Pierre-Augustin Caron de. Le mariage de Figaro. In: OEuvres, op. cit., p. 365.

31 Apud AUERBACH, Erich. Os apelos ao leitor em Dante. In: Ensaios de literatura ocidental - filologia e crítica. Org. Davi Arrigucci Jr. e Samuel Titan Jr., trad. Samuel Titan Jr. e José Marcos M. de Macedo. São Paulo: Duas Cidades; Editora 34, 2007, p. 119. 
A cena é também preparada pela sétima do ato anterior, quando o jovem pajem confessa à camareira não resistir às mulheres, muito menos à Condessa, e, como Alcoforado fará anos depois, rouba a fita com que Suzanne prendia os cabelos de sua ama, a "linda madrinha", nas palavras do rapaz.

No referido "Prefácio", sempre em defesa das acusações da censura, Beaumarchais chama a atenção para a pureza de intenções da Condessa, que, se usou de ardis, não foi com o objetivo de trair o marido, mas sim de impedir seus deslizes e reconquistá-lo. "Para que essa verdade vos atinja mais" - afirma aos leitores e possíveis espectadores - "o autor opôs, a este marido pouco delicado, a mais virtuosa das mulheres por gosto e por princípios." ${ }^{2}$ Concorda que houve um "momento crítico" e que a benevolência da Condessa em relação ao rapaz, seu afilhado, poderia transformar-se em desejo perigoso, mas concluiu que não há virtude sem sacrifício. "O que nos agrada na Condessa" - continua - "é de vê-la lutar francamente contra um desejo nascente que ela própria reprova e contra ressentimentos legítimos." ${ }_{33}$

Apesar dos argumentos plausíveis de Beaumarchais em resposta aos censores, o "affair" Condessa / Cherubino não deixou de alimentar a fantasia dos continuadores da comédia. ${ }^{34}$

Quanto a Leonor, fica evidente seu envolvimento, embora de caráter apenas emocional e não sensual, conforme mandava o código cortês, ${ }^{35}$ o que não a inocenta de infidelidade. O Duque já o dissera na cena final: "Fizesse eu correr o mar entre ambos, que de um lado a outro voaria o pensamento do adultério! Mar de sangue correrá entre ambos" ${ }^{36}$

"Pour que cette vérité vous frappe davantage, l'auteur oppose à ce mari peu délicat la plus vertueuse des femmes par goût et par principes". Oeuvres, op. cit. p. 363.

33 "Ce qui nous plaît dans la comtesse, c'est de la voir lutter franchement contra un goût naissant qu'elle blâme et des ressentiments légitimes". Oeuvres, op. cit. p. 363.

34 Cf. Marandon (1758-93) que em 1785 escreveu L'emprisonnement de Figaro, rebobinando a peça, pois nela um cabeleireiro vindo da França e instalado em Sevilha conta a Almaviva a história das Bodas, falando do "amor apaixonado" de Rosina pelo pajem. O próprio Beaumarchais retoma o tema em La mère coupable (1792), em que Almaviva descobre cartas que falam da relação da Condessa com Cherubino, de que resultou um filho. (Cf. texto e comentários à peça in BEAUMARCHAIS, Pierre-Augustin Caron de. Le mariage de Figaro. Op. cit.)

René Nelli, em L'érotique des troubadours (1963), distingue entre o "amor cavaleiresco", baseado na fidelidade e reciprocidade, e o "amor cortês", complementar do primeiro, nunca realizado, entre um seguidor humilde e uma dama de origem nobre. (Apud BOASE, Roger. The origin and meaning of courtly love, op. cit.).

36 DIAS, Gonçalves. Leonor de Mendonça. Op. cit., ato III, quadro IV, cena 7, p.113.

Teresa revista de Literatura Brasileira [12|13]; São Paulo, p. 226-243, 2013 • 235 
Na peça de Beaumarchais a relação dos esposos é baseada no poder, justificando o adultério masculino. Ouçamos, por exemplo, as palavras do Conde dirigidas à Condessa, que está disfarçada da criada, a quem ele deseja conquistar: "O amor... o amor é uma invenção do coração: a história verdadeira é a do prazer". E à pergunta da Condessa travestida, “O senhor não ama mais a Condessa?”, ele responde: “Oh, eu amo muito a Condessa: mas três anos de vida em comum transformam o casamento numa coisa tão respeitável!". 37

Em Leonor de Mendonça, "peça de virtualidades" em que os atos às vezes se equilibram mal no terreno escorregadio das intenções, o que foi corretamente avaliado pelos críticos, a relação entre marido e mulher tem uma face clara, principalmente nas falas de Leonor, quando comenta o casamento arranjado, a preferência do Duque pela religião, e não pela mulher etc. Mas a peça possui também uma face nebulosa, facilitada pelo jogo dramático.

Marlene de Castro Correia observa com finura que, na construção da cena em que a fita da Duquesa é roubada, depois perdida, recuperada em seguida e finalmente devolvida, há o traçado de um movimento sinuoso que pode ser considerado dominante na peça, apontando assim para "uma tensão entre o dito e o não dito [...]" ${ }^{38}$

Pelo temperamento vital, observado à hora em que luta pela vida, pela mocidade, pela falta de experiência, mas também pelo desejo nascente, contra o qual luta confusamente, ${ }^{39}$ Leonor tem algo de um bovarismo avant la lettre: estando na província com o marido, anseia por voltar à corte, aos bailes e divertimentos, pois não consegue dormir "em terras pequenas". ${ }^{\circ}$ Mais do que isso, ela parece às vezes inocentemente leviana, não demonstrando sensibilidade para interpretar falas ou ações do marido, a quem não ama, de quem tem medo, respeitando-o por obrigação.

Décio de Almeida Prado ${ }^{41}$ observa que Leonor, à hora da morte, rompe a convenção romântico-medieval, instalando-se definitivamente no realismo psicológico, pois, à sugestão de Alcoforado de arriscar a vida jogando-se pela janela para salvá-la, ela retruca que a morte do rapaz "seria terrível testemunho" contra sua inocência. "Em

37 Idem, ato V, cena 7, p. 475.

38 CORREIA, Marlene de Castro. Introdução a "O teatro de Gonçalves Dias". In: Teatro completo, op. cit.

39 No Prefácio a sua peça, Beaumarchais descreve a Condessa como lutando "franchement contre um goût naissant qu'elle blâme et des ressentiments légitimes" (BEAUMARCHAIS, Pierre-Augustin Caron de. Le mariage de Figaro, op. cit., p. 363).

40 DIAS, Gonçalves. Leonor de Mendonça. Op. cit., ato I, quadro I, cena 2, p. 20.

41 PRADO, Décio de Almeida. Leonor de Mendonça: amor e morte em Gonçalves Dias. In: Esboço de figura homenagem a Antonio Candido. São Paulo: Duas Cidades, 1979, p. 242.

236 • AREAAS, Vilma. Variações do "amor cortês" 
síntese", conclui o crítico, "o que interessa é a prova de sua inocência, não a vida de Alcoforado." Atitude que se faz cristalina no momento em que surge o escravo com o manchil da cozinha para decapitar o rapaz, pois não é a ele que se dirige a compaixão de Leonor, que clama desvairada: "Meu Deus! Compadecei-vos de mim”. Décio conclui que Alcoforado já havia saído de seu pensamento.

Nessa quebra do efeito dramático e da forma romântica se faz visível o "humor sorrateiro" de Gonçalves Dias, nas palavras de Vagner Camilo ${ }^{42}$ ao retomar "O sorriso de Gonçalves Dias" de Carlos Drummond de Andrade, ${ }^{43}$ definido como "um certo sorriso que secretamente abre caminho na poesia carrancuda" das Sextilhas. Neste momento o "grandioso" sucumbe ao "demasiado humano", criando uma ironia sem efeito cômico-risível, que é o que acontece no desfecho de Leonor de Mendonça.

Se fizermos uma leitura atenta do primeiro ato, a partir da cena 6 , também percebemos muitos matizes e falas reticentes, elisões desestabilizadoras do sentido aparente. Por exemplo, d. Jaime se aproxima de Leonor "feliz e venturoso", mas interrompe as próprias palavras ao ouvir vozes: "Não faláveis a alguém?".

Sabe então que Alcoforado acabara de sair e que tencionava partir para a África. Intempestivamente e claramente enciumado, o Duque afirma então à sua mulher que o jovem deseja ser tratado "com mil atenções" e "vegetar", no que é contraditado por ela, que afirma a intenção de Alcoforado: alcançar "morte honrosa ou nome glorioso". Imediatamente, o Duque deseja caber no mesmo modelo e replica que um dia talvez "fujamos da vossa muita amada companhia" para combater os infiéis.

Julgo não ser absurda a interpretação de tais palavras como o desejo de competir com Alcoforado e parecer valoroso aos olhos da mulher.

Neste preciso momento ele recorda o motivo que o trouxera aos aposentos da Duquesa, mas, antes de o revelar, inicia uma longa inquirição para saber dos desejos dela:

- Dizei-me, duquesa, não vos apraz esta vida um pouco rústica que viemos aqui buscar neste desterro?

Ela responde com outra pergunta.

42 Cf. CAMILO, Vagner. Nos tempos de antão. Considerações sobre as Sextilhas, de Gonçalves Dias. Op. cit., p. 110 ss., que examina com minúcia esse procedimento gonçalvino.

43 ANDRADE, Carlos Drummond. O sorriso de Gonçalves Dias. In: Poesia e prosa. Rio de Janeiro: Nova Aguilar, 1992, p. 1329 (apud Vagner Camilo, op. cit., p. 110 ss.). Drummond não deixa de sugerir que o humor percebido possa também ser atribuição de leitores distanciados no tempo. 
- Não é do meu dever seguir-vos para onde vos aprouver levar-me?

- Não vos falo do vosso dever; trata-se de vós, do vosso gosto; pergunto-vos se não amais esta vivenda. ${ }^{44}$

- Duque, poderia eu estar melhor algures que na vossa companhia?

Com impaciência provável, talvez alguma ironia melancólica (não há informações nas rubricas), ele comenta: “- Sempre boa, afável e condescendente!”. ${ }_{5}^{5}$ Em seguida, comparando a ermida do bosque, onde sempre se refugia, a "um pensamento de virgem, aformoseado pelo silêncio e pelo pudor" ${ }^{46}$ inspira a réplica de Leonor:

- Eu concebo, senhor duque, que vós partais sempre com a felicidade no coração, e que sempre torneis...

D. Jaime a atalha com vivacidade:

- ... mais feliz do que parti.

Tais revelações de confissão amorosa a meias tintas são retomadas na cena 8, quando o Duque a convida com insistência para acompanhá-lo à caça, seduzindo-a com o passeio e com a possibilidade de a mulher experimentar "o vosso belo palafrém andaluz que há pouco vos chegou de Espanha". "Quereis vir?"A isso Leonor responde: "Mandais.... E ele atalha: "Não, peço-vos". Por fim ela concorda com o passeio, d. Jaime está nitidamente ansioso ("Vireis já, não é assim"?), nomeia-a "minha bela guerreira", enquanto a Duquesa pensa em Alcoforado, achando que o veria "pela última vez". A oposição dos sentimentos dos esposos não pode ser mais clara. No quadro II, sabemos do motivo de todo o diálogo, isto é, a permissão do marido para que ela retornasse à corte. Possivelmente sem alegria o Duque conclui: "A

44 A palavra "vivenda", além de significar "casa", "morada", pode também se referir ao próprio Duque, a seu modo de vida.

45 Cf. do quadro II a cena 3, quando d. Jaime implora a Leonor "sequer por um instante, sequer uma vez um desejo vosso, uma vontade vossa" etc. O desejo que ele demonstra de saber o desejo da mulher é evidente.

46 Não esquecer a associação da mulher com a religião ou com a Virgem Maria, segundo certa sugestão crítica da lírica medieval, enlace perfeitamente exemplificado nas palavras do Duque. 
corte tem muitas festas, muita pompa, muitos divertimentos: precisais deles, bem o sabemos".

Finalmente à hora da morte, quando Leonor afirma que ele se casara "contra o seu querer" com uma mulher que não ama, ele responde de modo cortante: "Quem me poderia obrigar, Senhora?".

Em suma, o que desejo explicitar é que, nesta peça "de virtualidades", nem tudo ainda foi explorado, principalmente quanto a d. Jaime, imobilizado no juízo dos leitores pela brutalidade do castigo imposto à mulher e pela definição que dele nos dá o próprio poeta em seu "Prólogo": apesar de considerar que, como Leonor, d. Jaime "só tem defeitos" e não vícios, ele também afirma que "O duque é severo porque insensível". ${ }^{47}$

No entanto, contrariando essas palavras, o que vemos é que Leonor não ultrapassa o convencional no juízo do marido, e ele se lastima por ela não o compeender em seus acessos de cólera, pois que são derivados de sofrimentos: “[...] já os não devíeis temer; não vos devíeis atemorizar quando vos não compadecêsseis de mim”. $4^{8}$ É justamente a doença psicológica e os acessos o que o leva a sacrificar-se e permitir-lhe amargamente a volta à corte: "Partireis, duquesa; jovem, nobre e formosa, não é com um homem como eu que deveis passar a vida". ${ }^{49}$

No citado "Prólogo", a virtualidade dos personagens se ajusta à compreensão que Gonçalves Dias demonstra quanto à criação literária que, segundo ele, escapa aos desígnios conscientes do autor: "Há, porém, entre a obra delineada e a obra já feita, um vasto abismo que os críticos não podem ver, e que os mesmos autores dificilmente podem sondar". ${ }^{\circ}$ Mais adiante ele confidencia aos leitores que, se os escritores contemporâneos à história afirmam que Leonor foi morta "por falsas aparências", na verdade sugerem "que não foram tão falsas as aparências como eles no-las indicam" ${ }^{51}$ Sem dúvida, na peça, o indício mais forte de infidelidade se afirma no pouco amor que a Duquesa sente pelo marido, na inclinação à fantasia e na cegueira quanto às canhestras tentativas de aproximação do Duque.

As suposições são facilitadas pela fina construção psicológica do drama que às vezes se envolve e se oculta nos véus dos presságios garrettianos de Frei Luís de Sousa,

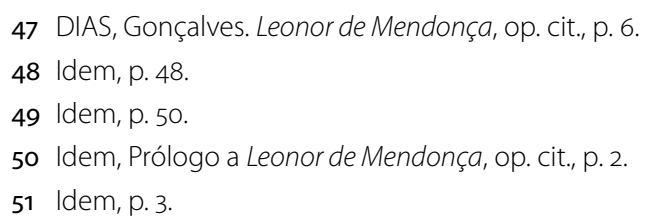


peça de 1844 que Gonçalves Dias certamente conhecia, e na dispersão da prosa de Bernardim Ribeiro, ${ }^{22}$ citado pelo poeta em seu "Prólogo", assim como por Leonor, numa menção truncada ao se confessar, antes da morte: "Criança me trouxeram de casa de meus pais...". ${ }^{53}$

Misturados aos devaneios amorosos e às desgraças, esses textos também deixam rastros que favorecem interpretações alternativas, reforçadas por alusões, das quais as mais explícitas encontramos nos lábios de Paula, ao comparar Alcoforado, primeiro a Hermigues (sic), o Traga-Mouros, ${ }^{54}$ lendário guerreiro e poeta da corte de Afonso Henriques, que supostamente roubou a amada moura para com ela se casar; em seguida Paula também se refere a Leonardo, "o cavaleiro namorado" do Canto de Os lusíadas ${ }^{55}$ que persegue Efire, "exemplo de beleza,/ Que mais caro que outras dar queria/ O que deu pera dar-se a natureza".

Em momento algum se duvida do desejo de Efire de lançar-se nos braços de Leonardo, "soldado bem-disposto,/ Manhoso, cavaleiro e namorado", ${ }^{6}$ mas se a ninfa protelava a entrega e fugia, era apenas para ouvir as súplicas do enamorado durante a perseguição amorosa, "... o doce canto,/ As namoradas mágoas que dizia”.57 Evidentemente as observações explícitas de Camões a respeito dos alegóricos habitantes da Ilha dos Amores não cabem na peça de Gonçalves Dias, mas a alusão é muito clara, mais significativa ainda por ser velada, e não deixa de criar sombras em torno do retrato unidimensional de Leonor.

BERNARDIM, Ribeiro. História de menina e moça. Variantes, introd., notas e glossário de D. E. Grokenberger prefácio de Hernani Cidade. Lisboa: Liv. Studium Ed., 1947.

53 "A prosa de Bernardim Ribeiro casar-se-ia maravilhosamente com os versos do Sr. Garrett", diz o poeta no Prólogo a Leonor de Mendonça.

54 O nome do cavaleiro é Gonçalo Hermingues, tipo fixado nas lendas, que teria caído em desgraça, acabando a vida como ermitão.

55 Camões, Os lusíadas, estrofe 76, edição fac-similada da edição comentada por Augusto Epifânio da Silva Dias. MEC, 1972.

56 Idem, estrofe 75

57 Idem, estrofe 82. 


\section{Variações do amor cortês}

Tan grave dia que vus conhoci

por quanto mal me ven por vos, senhor!

D. Afonso Sanches

No correr deste texto vim semeando traços do amor cortês segundo o imaginava um certo romantismo, evidentemente colorido pelas contingências de sua época. O assunto estava no ar à época de Leonor de Mendonça. Basta-nos pensar no Romanceiro coligido por Garrett (1843 e 1850) e na publicação do Cancioneiro d’el Rei D. Diniz (1847) e de "O livro das cantigas" o Conde de Barcellos (1849), respectivamente por dr. Caetano Lopes de Moura e Francisco Adolfo de Varnhagen, dois brasileiros. ${ }^{58} \mathrm{O}$ romance histórico com cenário medieval e tintas de novela da cavalaria também não andava longe e pode ser visto em Eurico, o presbítero (1848), de Herculano.

Se o programa estético romântico procurou revitalizar o passado e as lendas nacionais, não nos esqueçamos de que Portugal era sentido como o passado do Brasil, segundo nosso poeta e conforme já o sentira também Gonçalves de Magalhães quando elegeu Antonio Josés9 como protagonista de sua peça, inauguradora de nosso romantismo. Assim é que entraram em cena códigos da convenção peninsular do amor-mito medieval - aliás, não existia um código único, repito, tal como foi supostamente exercido pela cavalaria dos séculos XII e XIII, quando se tornou necessária a organização da paixão por meio de satisfações simbólicas. ${ }^{60}$

Aqui entra o "serviço" amoroso principalmente prestado a mulheres casadas, a finamors, "segundo o qual se impunha o segredo quanto ao nome da dama objeto do amor e do canto trovadoresco". ${ }^{61}$ Esses códigos são vistos nas duas obras em

Cf. VIEIRA, Yara. Os estudos medievais no Brasil: peso (ou leveza) de uma tradição. Anais, VII EIEM: Encontro internacional de estudos medievais. Org. Roberto Pontes e Elizabeth Dias Martins. Fortaleza/Rio de Janeiro: CAPES/ Xunta da Galicia/ ABREM, 2009, p. 75 ss.

59 Embora nascido no Brasil em 1705, aos seis anos acompanhou o pai a Lisboa, levados pela Inquisição; lá foi assassinado pela mesma instituição em 1739. Se é possível fazer tal diferença, o Judeu, como é conhecido, é mais português que brasileiro.

6o ROUGEMONT, Denis. O amor e o Ocidente. Trad. de Paulo Brandi et al. Rio de Janeiro: Guanabara, 1988.

61 Cf. VIEIRA, Yara Frateschi. O nome da dama. Signum, revista da ABREM, Associação Brasileira de Estudos Medievais, nº 7, 2005. Citando Carolina de Michaelis, de quem publicou, com outros pesquisadores, Glosas 
meio ao jogo dos gêneros e misturados a imposições do final do século XviII e do $\mathrm{XIX}$, entre as quais incluímos o que se pode chamar de feminismo, pois as duas peças foram também lidas como um libelo a favor das mulheres contra o despotismo dos homens. Com isso já anunciavam o teatro do final do século XIx. Beaumarchais já o afirmara em seu prefácio: "car nos jugements sur les moeurs se rapportent toujours aux femmes". ${ }^{2}$

Se o amor cortês é uma arte com seu próprio código de regras, assim como a cavalaria, Leonor é uma personagem diferenciada por suas próprias contradições, como já foi analisado, à mercê da fatalidade "cá da terra". No mundo das convenções teatrais ela habita dois mundos, entre a idealização romântica e o realismo psicológico do teatro do final do século, entre o mundo cavaleiresco e o autoritarismo realista do poder aristocrata. Podemos mesmo dizer que é o jogo terso da composição o que não deixa que se rompam os fios da adequação estético-teatral da personagem, que se ajusta de forma indecisa no modelo do drama romântico. Talvez a causa seja que a obra, rica e variada, contenha "o germe de certos desequilíbrios" cultivado pelas gerações seguintes? ${ }^{63}$

Quanto à disposição amorosa de Leonor, Décio de Almeida Prado chega a ponderar que "o adultério por desfastio, por desforra da imaginação sobre a realidade, não anda longe: Leonor de Mendonça é de 1846, Mme. Bovary, de 1857". ${ }^{64}$

À ligação da obra com Schiller, proposta por Ruggero Jacobbi, certamente por conta da tradução feita pelo poeta, Décio de Almeida Prado ${ }^{65}$ com acerto prefere outros modelos: o Antony, de Alexandre Dumas, ou o Chatterton, de Vigny, ambas envolvidas com a questão do feminismo. Diz este último: "De frayeur en frayeur tu passeras ta vie d'esclave. Peur de ton père, peur de ton mari un jour, jusqu' à la délivrance". ${ }^{66}$

marginais ao Cancioneiro Medieval Português (Coimbra/Santiago de Compostela/Campinas: Universidade de Coimbra/ Universidade de Santiago de Compostela/ Editora da Unicamp, 2004) - Yara escreve que "o trovador galego-português, 'obediente às regras do amor', costumava silenciar o nome da amada, mas, quando 'ensandecido' de amor, podia chegar a nomeá-la, às vezes de forma indireta, e outras muitas de forma totalmente explícita". Há que se observar, na exigência do motivo, a diferença entre Provença e Portugal, onde as protagonistas eram "meninas em cabelo", portanto solteiras, não havendo necessidade explícita da ocultação do nome.

62 BEAUMARCHAIS. Oeuvres, op. cit., p. 362.

63 CANDIDO, Antonio. Formação da literatura brasileira. Rio de Janeiro: Ouro sobre Azul, 2006, p. 403.

64 PRADO, Décio de Almeida. Leonor de Mendonça - amor e morte em Gonçalves Dias. Op. cit., p. 237.

65 Idem, p. 257.

66 VIGNY, A. Théâtre. Paris: E. Flammarion, s.d, tome premier, 198 (Apud Almeida Prado, Leonor de Mendonça: amor e morte em G. Dias, op. cit., p. 257).

242 - ARÊAS, Vilma. Variações do "amor cortês" 
Mas Almeida Prado aponta também Tristão, mito definido como "fenômeno histórico de origem propriamente religiosa", como quer Rougemont, onde encontramos o amor-paixão e a ligação do amor com a morte.

Conforme observado anteriormente, em seu "Prólogo", notável para a época e para o lugar, Gonçalves Dias desloca a fatalidade clássica para o rés do chão: "Se a mulher não fosse escrava, como é de fato, d. Jaime não mataria sua mulher. Houve nessa morte a fatalidade, filha da civilização que foi e que ainda é hoje”. ${ }^{67}$

Essas palavras, sem dúvida, se encontram com as de Beaumarchais, e podem ser aproximadas até certo ponto do espírito com que abalam a convenção teatral. Em O casamento de Fígaro toda a ação deriva das mulheres: Suzanne e a Condessa é que movem os cordéis, tecendo pactos e teias de muitos fios. A peça em seu limite dá razão às mulheres. Além disso, se o par de criados tradicionalmente funcionava como contraponto subalterno dos patrões, agora "desponta uma nova humanidade", os criados triunfam do nobre sob os aplausos dos espectadores. No limite a comédia pode ser considerada uma encenação antecipatória do desmoronamento da sociedade aristocrática, o que fez a baronesa d'Oberkirsch escrever em suas Memórias: “é uma obra-prima de imoralidade, e mesmo de indecência [...]. Os aristocratas, a meu ver, revelaram falta de tato e de juízo indo aplaudi-la [...]. Arrepender-se-ão disso mais tarde". 68

Será esse espírito crítico-analítico dos autores o que também acrescenta novas cores ao sentido do amor cortês medieval, deslocando-o de sua posição central ao misturá-lo a outros fios e a novas contingências.

Vilma Arêas é professora da Universidade Estadual de Campinas, autora de Clarice Lispector com a ponta dos dedos (Companhia das Letras, 2005); Curvas e quinas da poesia romântica (Edusp, 1998); Décio de Almeida Prado - um homem de teatro (Edusp, 1997); Na tapera de Santa Cruz (Martins Fontes, 1987); La mujer en la cultura brasileña (El Urogallo, 1995), entre outros.

67 Gonçalves Dias. Prólogo a Leonor de Mendonça, op. cit. p. 4-5.

68 Cf. "Introdução" (vii-xix) de Antonio Monteiro Guimarães. In: As bodas de Fígaro-Mozart, Da Ponte, Beaumarchais, 1991, p. X. 